Int. J. Electrochem. Sci., 11 (2016) $5819-5828$

\title{
Improving Power Conversion Efficiency of P3HT/PCBM based Organic Solar Cells by Optimizing Graphene Doping Concentration and Annealing Temperature
}

\author{
Shang-Chou Chang ${ }^{1, *}$, Yu-Jen Hsiao ${ }^{2,}$, Tien-Chai Lin ${ }^{1}$, To-Sing Li ${ }^{1}$, Syu-An Zeng ${ }^{1,}$, Chen-En Yu ${ }^{1}$ \\ ${ }^{1}$ Department of Electrical Engineering, Kun Shan University, Tainan City 71010, Taiwan \\ ${ }^{2}$ National Nano Device Laboratories, Tainan City 74147, Taiwan \\ *E-mail: jchang@mail.ksu.edu.tw
}

doi: $10.20964 / 2016.07 .72$

Received: 19 April 2016 / Accepted: 23 May 2016 / Published: 4 June 2016

\begin{abstract}
Graphene (GN) doping concentration and annealing temperature in blended poly (3-hexylthiophene) and [6,6]-phenyl C61 butyric acid methyl ester (P3HT/PCBM) with GN (P3HT/PCBM /GN) based organic solar cells (OSC) were investigated. Results indicate the power conversion efficiency (PCE) of $\mathrm{P} 3 \mathrm{HT} / \mathrm{PCBM} / \mathrm{GN}$ based OSC can be efficiently increased by $3 \mathrm{wt} \% \mathrm{GN}$ doping and $120^{\circ} \mathrm{C}$ annealing. The OSC doped with 3 wt $\%$ GN exhibited the highest PCE among OSC doped with 0 10 wt\% GN under the same annealed condition: unannlealed status and $120^{\circ} \mathrm{C}$ annealing. The PCE of $120^{\circ} \mathrm{C}$ annealed OSC doped with $3 \mathrm{wt} \% \mathrm{GN}$ is 2.81 , which is almost two times higher than that doped with 10 wt $\%$ GN. Thermal desorption spectra of unannealed P3HT/PCBM /3 wt\% GN show two desorption peaks at around 130 and $182^{\circ} \mathrm{C}$ resulting from water vapor. The two temperatures are close to the glass transition temperature of PCBM and melting temperature of P3HT, respectively. The $120^{\circ} \mathrm{C}$ annealing on P3HT/PCBM/3 wt\% GN can make both P3HT and PCBM have relatively good crystallization compared with unannealed status and $170^{\circ} \mathrm{C}$ annealing. Good crystallization makes charge carriers transport easily in P3HT/PCBM/3 wt \% GN based OSC.
\end{abstract}

Keywords: power conversion efficiency, P3HT/PCBM, grapheme

\section{FULL TEXT}

(C) 2016 The Authors. Published by ESG (www.electrochemsci.org). This article is an open access article distributed under the terms and conditions of the Creative Commons Attribution license (http://creativecommons.org/licenses/by/4.0/). 